\title{
'Good to know': An Exploration of the role and Influence of Professional Ethics in ICT Bodies of Knowledge (BoKs)
}

\author{
Clare Thornley ${ }^{1}$, Wanda Saabeel ${ }^{2}$, Shane McLoughlin ${ }^{3}$ and Sinéad Murnane ${ }^{1}$ \\ ${ }^{1}$ Innovation Value Institute, Maynooth University, Ireland \\ ${ }^{2}$ Promanad, Rotterdam, The Netherlands \\ ${ }^{3}$ LERO, Innovation Value Institute, Maynooth University, Ireland \\ cthornley@clarityresearch.eu \\ wandasaabeel@promanad.nl \\ shane.mcloughlin@mu.ie \\ sinead.murnane@gmail.com
}

\begin{abstract}
As our dependency on ever-more complex, opaque, and ubiquitous information and communication technologies (ICTs) increases, ethical concerns about the development of those technologies are also rising. One approach to mitigate these concerns is to improve the maturity of the ICT profession through codification of its knowledge base and professional ethics. In this paper, some key theoretical approaches to ethics with a long-established tradition within Philosophy are explored and how these approaches may manifest in the codification of knowledge within ICT Bodies of Knowledge (BoKs) is discussed. BoKs provide a common vocabulary and knowledge inventory to aid communication and encourage shared values and practices, particularly in emerging professional areas such as the ICT profession. Thus, identifying and understanding how ethics are codified in ICT BoKs is important for maturing ICT professional practice in general, and more specifically, for the resolution of ethical concerns. This paper 1) explores considerations and approaches to how ethics are incorporated within ICT BoKs, and 2) conducts content analysis on how ethics are codified within the content structure of ICT Boks. It is found that theoretical ethical approaches are rarely explicated cited in BoKS though, in the more mature BoKs, the discussion of ethics does include consideration of most of the major philosophical approaches. The implications of how knowledge about ethics is described and integrated into the wider knowledge infrastructure of the ICT profession including curriculum guidelines and accreditation processes is discussed. In a wider contribution to the Knowledge Management discipline, potential lessons to increase maturity for other emerging professions through the development of BoKs are also outlined.
\end{abstract}

Keywords: Bodies of Knowledge; knowledge codification; ethics; ICT profession; Knowledge Management; professional education

\section{Introduction}

Knowledge Management (KM) concerns knowledge, but what kind of knowledge is ethics? This is not only a question for individuals but also plays out in the workplace and wider society. How can we know what is 'good' and how can we get better at doing it? If we have better knowledge of what 'good' is and how to behave in ethical ways, does this make it more likely that people's behaviour will improve? The concept of professional ethics is familiar within our understanding of established professions, such as Medicine or Law. If professionals have expert knowledge and power over important parts of our lives, for example our health, we expect them to be responsible and ethical in how they operate. We also expect them to have knowledge of their own professional guidelines and to know how they might work in practice. In contrast, professional ethics are less defined or understood in newer or emerging professions such as the Information and Communications Technology (ICT) profession. The question of how the ethics of emerging ICT professions are codified and managed is becoming progressively more important in light of society's growing intertwinement and dependence on ICT, particularly given newer technologies such as Al and IoT (Lemonne, 2018). Many major safety critical infrastructure systems, for example, are increasingly dependent on ICT. As the complexity, iteration, and pervasiveness of ICT in all facets of life increases, and as significant risks of negative impacts of ICT emerge, public concern about potential ethical implications also increases. Simultaneously, as these technologies develop, new professions start to emerge around them. As these professions mature, their knowledge is codified, and processes are put in place to consolidate and share knowledge, as well as develop a shared sense of ethical professionalism. Over time, knowledge about ethics becomes more embedded within the profession. Professional ethics is distributed throughout all professionalism documentation, i.e. codes of ethics, certifications, accreditation, etc. Ethical issues or questions are addressed in a more integrated fashion and are seen to shape other areas of professional knowledge. 
As professions develop, they generally codify their expert knowledge in a structured document described as a Body of Knowledge (BoK). A BoK is a structured representation of the proposed and/or practised knowledge needed to function as a profession, as well as its scope or jurisdiction. In many cases, these BoKs are described as a reference guide to 'the Body of Knowledge'. Thus, they are often explicitly defined as a partial 'snapshot' of the full Body of Knowledge, which exists in multiple publications and the expertise of professionals. These are nearly always developed by a relevant professional body or organisation, though some can be developed through government policy initiatives. Importantly, these often explicitly cover some description of professional ethics within that domain as well as often implicitly reflecting an ethical posture in various ways. The inclusion and degree of ethical knowledge in BoKs (or indeed, its exclusion) is itself an ethical stance. The very existence of BoKs and their knowledge claims in identity forming and empowerment of groups has ethical implications. Similarly, a BoK's knowledge claims and their application in structuring or producing a 'legitimate' profession may have wider societal ethical implications (Greenfield, 2017). A BoK invariably reflects ethics, explicitly or implicitly, which will have intentional and unintended ethical implications. Thus, both knowledge and ethics are central to the concept of professionalism (Saks, 2012). BoKs do not operate in isolation but both represent and influence the education, training, and practice of the profession, through books, curricula, accreditation, etc.

Getting better at developing usable and relevant BoKs, as well as considering and incorporating ethics, is an important current policy and social issue for the ICT profession (EU Commission, 2018). Despite this increased policy focus on ethics and ICT related BoKs, they have received little corresponding academic attention. In light of this, this paper examines the current state of play regarding the integration of ethics within ICT professional BoKs. The following research questions guide this study:

\section{RQ1 How is ethics codified within the content structure of ICT professional bodies of knowledge?} RQ2 How does the treatment of ethics in BoKs relate to the main ethical theoretical approaches?

To address these questions, we begin by (1) exploring existing literature at the intersection of ICT Professionalism, BoKs, and ethics. We then (2) conduct content analysis on prevalent high-level ICT BoKs that influence the ICT profession. Furthermore, (3) we select three BoKs that have the highest level of ethics integration and we analyse them further to gain deeper insights into their approach to ethics.

Finally, we carve the path to a research agenda connecting ethics and its relationship to professional knowledge. The nature of how ethics can be integrated into BoKs and how this may be linked to known ethical theoretical approaches is discussed. The possible implications for more effectively integrating ethics into other tools or aspects of professionalism are then outlined. Whilst we contribute to the understanding of knowledge about ethics within the ICT profession, insights gained may also be applicable to other professions, particularly those newly emerging.

The contribution of this study is threefold. It is the first analysis of how knowledge about ethics is codified in ICT BoKs and how this relates to wider ICT professionalism. Secondly, in the more detailed analysis of the high maturity BoKs, it develops an initial framework for how the three main ethical approaches relate to different approaches to discussing ethics in ICT professionalism tools and documentation. Thirdly, arising from these findings, it discusses the ways in which this may increase our understanding of the relationship between knowledge, ethics, and professionalism. This is an important contribution to KM both theoretically and practically, informing approaches to improving how knowledge about ethics is managed and developed within any professional sphere. Getting better at understanding the nature of professional knowledge and how it relates to professional ethics is only going to get more important as expert knowledge becomes increasingly specialised.

The paper is structured as follows. In section 2, we overview the core concepts of this paper: : ICT Professionalism; Bodies of Knowledge (BoKs); Curriculum Guidelines and Accreditation; Ethics; Professional Ethics. The relationship between Knowledge and Ethics is also discussed. In section 3, we outline our method for BoK selection and approach to analysis. Section 4 presents the results of analysis and introduces the framework of the key themes and ethical theoretical approaches. Section 5 is a discussion of the potential impact of how different approaches to the codification, description and integration of ethics within professional BoKs may influence how ethics is incorporated or not into professional identity and practice. Finally, section 6 draws some conclusions on the implications of this study for KM as a discipline and how insights from ICT BoKs may have 
possible lessons for other emerging professions. This concludes with some suggestions for future research on the topic of ethics and knowledge within the ICT profession.

\section{Literature Review}

In this section, we discuss the nature and scope of ICT as a profession, as well as significant developments in relation to research and policy linking the ICT profession with ethics. The major theoretical approaches to ethics are introduced with some discussion about how they manifest in the context of ICT. It also covers the focus of this paper, i.e. the nature of Bodies of Knowledge (BoKs), and associated professional documentation including curriculum guidelines and codes of ethics in more detail. This general overview provides context to the subsequent discussion as well as the wider research agenda of ethics, knowledge, and ICT professionalism proposed in the conclusion.

\subsection{ICT professionalism}

ICT is a hard topic to define clearly and professionalism is a disputed concept. Grasping these combined concepts is therefore rather complex. The 'European Centre for the Development of Vocational Training' (CEDEFOP) defines ICT professionals in terms of, 'conducting research, planning, designing, writing, testing, providing advice and improving information technology systems, hardware, software and related concepts for specific applications. They develop associated documentation and design, develop, control, maintain and support databases and other information systems to ensure optimal performance and data integrity and security' (CEDEFOP, 2016). This implies the scope of an ICT professional can be quite varied, in terms of research, practice, and ICT focus, with ethical considerations more explicitly evident concerning data integrity and security.

In relation to the exact nature and value of the professions, there is a long disputed historical debate on their role, as observed by Saks (2012), whilst Eraut (1994) discusses 'newer' professions such as education and their struggles to gain equivalent autonomy and status compared to more established professions. Within ICT, there have also been some robust debates on the relevance of professionalism to the field. In Australia, for example, one author argued 'that Computer Societies have been bewitched from the pursuit of their humanistic objectives by the lure of professional status' (Holmes, 1974, p.127). Here we see that professionalism, as well as incorporating ethics, may sometimes be perceived as a distraction from ethics. Despite these debates, authors generally agree on the importance of a profession's relationship to at least some expert knowledge, and that some ethical approach be adopted. As expert knowledge is key to professionalism, with ethics also important in this regard, we examine how they can be connected. Ethics in terms of professionalism is also distinct from general ethics as it explicitly applies only to those within the profession: the possession of expert knowledge bestows particular ethical obligations.

Connecting ICT professionalism with ethics is particularly salient in relation to high profile disasters and frauds caused or enabled by ICT, which can severely weaken public trust in ICT and those who develop and use these systems. In parallel, there is growing concern about ICT ethics and an emerging consensus that ICT ethics must be explicitly addressed (van der Linden et al., 2017) as part of the general drive towards professionalism. As the ICT profession is relatively immature compared to the well-established professions of Law and Medicine, and as society's dependence on ICT increases, it is imperative that standards improve. Furthermore, maturing the ICT profession can have associated economic and social benefits. For example, this could include a reduction of risks posed by ineffective development and use of ICT, due to poorly trained ICT labour with inadequate ethical awareness.

There has been some prior research and policy work on maturing the ICT profession within the European context (McLaughlin et al., 2012) which has developed a model of ICT professionalism based on literature analysis and data collection from stakeholders. The model consists of four building blocks: a) Competences; b)Bodies of Knowledge; c) Education and Training; and d) Professional Ethics. 'Competences' are primarily concerned with workplace skills, which can be practically demonstrated; 'Education and Training' are concerned with improving consistency and standards, in some cases through certification; 'Bodies of Knowledge' concern developing an agreed core structured knowledge reference; and 'Professional Ethics' is about improving the level of ethical knowledge, behaviour, oversight and responsibility within the ICT profession. 


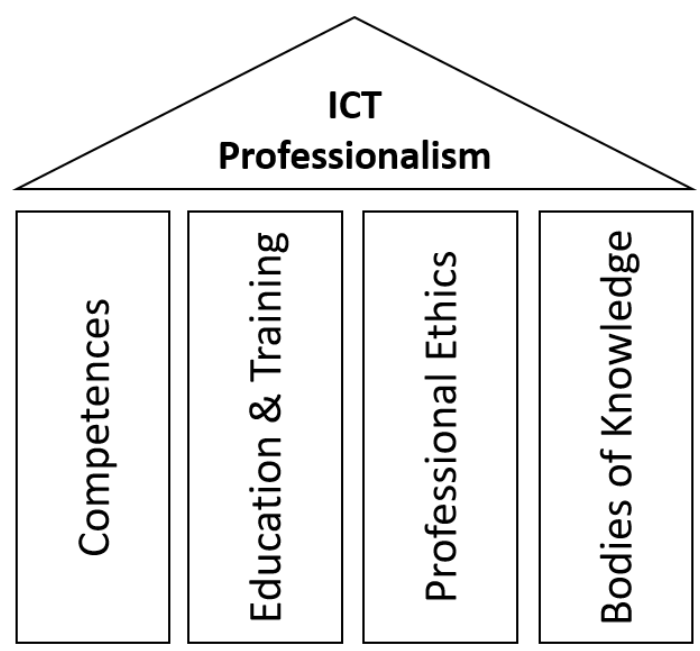

Figure 1: The Pillars of ICT Professionalism (adapted from McLaughlin et al., 2012)

The European Commission's policy drive for developing ICT professionalism, as part of the overall Digital Europe Strategy (The European Commission, 2019), aims at maturing these building blocks in an integrated way. The key question, however, is: how exactly can these building blocks be integrated both conceptually and in practice? It is not too difficult to integrate a competence framework into a training programme (Sanz et al., 2018), nor is it problematic to consider how to use a Body of Knowledge as part of developing competences. Ethics, however, does present a challenge in terms of integration, as it appears to have important differences from the other types of professional knowledge. The path is less clear than the other aspects of professionalism as people can disagree on ethical priorities and there are some cultural differences (Sherry, 2013). A recent review of ethics as part of ICT policy revealed both core agreements and differences within the EU, for example, former Eastern bloc countries held different perspectives than some Western European countries (Thornley et al., 2018).

Indeed, dilemmas and complexity are often highlighted as key parts of ethics and ICT (Runciman, 2019; Thornley et al., 2011). Some areas of ICT raise particular concerns in terms of transparency and accountability, such as Artificial Intelligence (Koene, Clifton and Hatada, 2019) and efforts have been made to map their internal workings to visible connections to known moral norms (Tubella et al., 2019). Many ICT professional areas are cross-sectoral in that they directly affect and support a very wide range of sectors outside ICT. Cyber security, for example, is critical to many sectors and articulating cyber security ethics in all these varied areas is challenging (Yaghmaei et al., 2017) with many complex ethical trade-offs. The potential ethical implications of the increasing role and ubiquity of data is a broad concern and this is addressed as a business issue in the professional literature (Lynch et al., 2016) as well as in the more academic sphere (Floridi and Taddeo, 2016). Regulating the ethics of emerging professions can also be seen as a challenge to their independent professional status in some cases (Eraut, 1994) and can be a difficult balancing act.

\subsection{Bodies of Knowledge}

Part of KM is about enabling knowledge sharing through effective codification. Bodies of Knowledge (BoKs) are explicitly designed to model, codify, and share common core agreed knowledge, normally for specific professional groups. A BoK is knowledge codified to make it easier for professionals to complete their duties and tasks. BoKs are both normative (this is what a professional should know, in some cases with priority areas defined) and descriptive (this is some detail on the content of knowledge that professionals need). Their content structure generally contains a section explaining the purpose, scope and intended audience. The knowledge they describe/define is grouped into categories/areas KA and subdivided into further knowledge items (KI) or units (KU).

From our study of ICT BoKs, regarding the 'types' of knowledge they include, it can cover concepts, models, theories, and methods. These can vary in the degree of abstraction depending on the nature of the profession and how specific the particular BoK is. Some BoKs allocate different knowledge items into specific levels of professional knowledge depending on how advanced or specialised they are. More commonly, some Knowledge Areas or Units are mandated as essential for all professionals, whilst others are allocated to specific professional sub sectors. The question of how to include ethics within ICT BoKs has received more attention recently, and will be discussed more in the findings section, but there are acknowledged tensions between demonstrating that 
'ethics' is everywhere for everyone and also including enough detailed ethics content to actually guide teaching and professional development. BoKs exist for many professions but are normally only discussed or critiqued when a nascent profession feels it needs one, e.g. recent work on requirements engineering (Penzenstadler et al., 2013), or when a major update is required, e.g. project management (Morris, 2001).

BoKs are explicit knowledge, according to Nonaka's (1994) distinction between explicit and implicit or tacit knowledge, as they are always written down or 'codified'. At the same time, they draw heavily on tacit knowledge as they are typically devised through consultation with experts. The method of their development generally involves a literature review of key sources to identify topics and new trends and then a consultative period (Sefton, Shea and Hines, 2011) to consolidate and attempt to reach consensus. While there is no single agreed method for development, this broad outline is used as a common approach (Morris, 2001; Morris et al., 2006) though different professions rarely acknowledge methodological input from other professional BoKs. So far in our literature review, we found no real input in BoK development from KM expertise on knowledge codification, such as expertise on improving elicitation methods (Gavrilova and Andreeva, 2012).

BoKs are not only a recent development but are discussed in an historical sense when studying books or artefacts that represent specialised ancient knowledge such as Shamanism (Rutz, 2013). They are often afforded a kind of reified status and are described as ontologies, 'representations of', and in some cases, have an almost totemic status (Durkheim, 1912) in symbolically externalising the shared identity of a profession. This is particularly notable in the rhetoric of BoKs in emerging professions, such as massage therapy (Sefton, Shea and Hines, 2011). They can be linked explicitly to the human body as part of a critique of the tendency to focus on learning and knowledge as purely cerebral rather than embodied (Peters, 2004; Claxton, Lucas and Webster, 2010). Indeed, the term 'Bodies of Knowledge' as opposed to, for example, 'Knowledge Reference Guide', does perhaps indicate that BoKs suggest an incorporation of knowledge into the physical practices of a group. In many cases, BoKs explicitly claim that they are merely a representative artefact of the actual Body of Knowledge, which only exists in the sum of all relevant literature and the expertise of professionals. Thus they can be both a codification and an acknowledgement of the limits of codification, with no sense of perceived contradiction. They are knowledge with a clear purpose and codification is seen as useful insofar as it furthers that purpose. A BoK, however, does not need to claim complete exhaustivity or exclusivity of all relevant knowledge.

BoKs concern issues of identity, developing or furthering professionalism and, in some cases, claiming and disseminating knowledge by formerly marginalised groups. A strong example of this is the women's movement in the 1970s. Up until that time, medical knowledge about women's bodies was owned and controlled by the predominantly male medical establishment. The seminal book 'Our Bodies Ourselves' (Hawley et al., 1971) was developed and published by women in an accessible form, which also incorporated the lived experience of women's embodied lives (Davis, 2007). Both the book and the associated discourse around its publication are fascinating examples of the role formalising knowledge can have in creating shared identity and empowerment. Thus, whether BoKs formally include ethics within their structure or not, they often have a value driven motivation in their formation, development, and dissemination. These developments are not without dissenting voices, such as recent discussion on the validity and usefulness of the SCRUM Body of Knowledge (Kim, 2020) and the ongoing debate on the validity and objectivity of the Psychiatry Profession's Classification Manual of Mental Disorders (Spiegel, 2005).

\subsection{Curriculum guidelines and Accreditation}

BoKs are part of a wider domain knowledge infrastructure, being increasingly allied to competence development through links with curriculum guidelines and competence frameworks (Morris et al., 2006) for their related professions. Curriculum guidelines are published by some ICT professional bodies and these provide more detailed specifications for the content, ordering, assessment, and delivery of courses. In some cases, the distinction between a BoK and curriculum guidelines is not completely clear cut. In any case, curriculum guidelines will refer to or include content from their associated BoK. If educational institutions then wish to have their courses accredited by the relevant professional body, they must include BoK content in their courses and structure it in line with the curriculum guidelines. In these cases, BoKs can have a particular influence as they flow directly into curriculum guidelines and are linked to curricula or course accreditation. This accreditation matters, as it demonstrates to potential employers that the course covers material deemed as essential and useful by the professional body. It can happen in different ways, sometimes quite directly as is carried out by the Australian Computing Society (ACS) and other times via another standards body as is done by the Association for Computing Machinery (ACM). The way ethics is included and integrated in the BOK and associated processes, 
if done well, should result in professionals entering the workplace with the required ethical knowledge and skills to apply it. Accreditation processes linking to a BoK that includes ethics will require the accredited institution include ethics tuition in its accredited ICT programme, often with quite directive guidance on how this must be done, e.g. integrated within modules and as a stand-alone module.

Competence or Skills Frameworks are used more in continuing professional development (CPD) and professional education. The inclusion of ethics in these furthers the integration of ethics into professional development and identity. This increases the potential role of ethics in BoKs, as there is a push from educators and employers to incorporate ethics in professional education. This is partly due to decreased public trust in professions per se and how high profile disasters (Gelles, 2019) and privacy leaks have decreased public trust in the ICT profession.

For example, the IEEE has recently completed extensive work on ethics for Al and autonomous systems (IEEE SA, 2020 ) in response to growing public disquiet. The IEEE's initiative incorporates educational guidance and is moving towards certification. The recently updated European e-Competence Framework (e-CF, 2019) now includes ethics as a Transversal Aspect designed to influence all competences. There is also currently a European project, Ethics4EU, on improving the teaching of ethics in computing curricula (Ethics4EU, 2021).

\subsection{Ethics}

Ethics generally concerns the study of what is right or wrong (or morals), why that might be so, and how humans engage with these concepts (Rachels and Rachels, 2019). This includes understanding systems of values, their application, and resulting implications. It has a long history of study within Philosophy and can be broadly grouped into three main approaches: virtue ethics; deontological ethics; utilitarianism/consequentialism. Virtue emphasises moral character and was initially developed by Aristotle (Aristotle, 350AD). Deontology emphasizes duties or rules and following those rules regardless of consequences. Finally utilitarianism (Mill, 1863) or consequentialism emphasizes the need to weigh up the positive and negative consequences of actions before deciding what is the right course of action to take (Hursthouse and Pettigrove, 2018).

Depending on which theoretical approach is taken, there are different perspectives on what knowledge about ethics might be. In virtue ethics, it is primarily implicit aspects of a person and their identity that guide behaviour, suggesting education and mentoring might be the best approach to impart knowledge/values and fully integrate it into a person's mindset and practice. In a rule-based approach, it suggests developing guidelines incorporating the correct ethical approach, and then ensuring everyone knows the rules and is compliant with them. This can include formulating and formalising code(s) of ethics. It may also include encouraging compliance by linking ethics codified in BoKs to graduate certification or even accreditation of the educational institute itself (i.e. curricula must be based on a BoK of which ethics is a part). The consequentialist approach requires the ability to weigh up the likely implications of actions, so it is in one sense knowledge or data driven. This is not straightforward, however, as the knowledge required to correctly assign ethical actions in different possible scenarios is different from gaining knowledge about what those scenarios may be. If taken at an individual level, it could also suggest a strong legal or compliance-based approach to ICT professional ethics, whereby ICT professionals would be obliged to behave in an ethical fashion due to fear of punitive legal sanctions if they do not. On a broad ICT level, this was part of the motivation for the heavy fines payable by organisations if they breach the guidelines of the European General Data Protection Regulation 2016/679.

Thus, we can see that one's view of 'what ethics is' affects the approach to improving ethical standards within a profession and how one might include ethics in a Body of Knowledge. It can also be dependent on one's view of the nature and role of a profession in relation to tackling ethics. The link between individual understanding and values, social or professional norms, and the connection between knowledge and practices are complex factors, which influence how knowledge about ethics plays out in a profession. There remains the concern that even if professionals are provided with very clear knowledge about ethics that they may still not necessarily apply them in professional practice. This is an issue with a long history, as Aristotle was concerned with the problem of 'weakness of will' which is the paradox, as he saw of it, of knowing what is right and still failing to take the right action.

\subsection{Professional Ethics}

Professional ethics is strongly related to the general use of the term ethics but is by its nature less universal. Professional ethics, as codified and articulated in various ways, are explicitly only applied to the profession in question, not the general population (Davies, 2004). Since part of what defines a profession is an organised 
group of people bound by defined specialist knowledge they use for a certain purpose, we argue that knowledge and its use have a more primary focus in professional ethics than in ethics in a general sense. Professional ethics incorporates a sense of duty or obligation towards the people who use and rely upon the professional's services who, by definition, do not share all of the professional knowledge or they would not need to consult them. There is often a power disparity between the professional and the client and the professional has an obligation to use their knowledge in the interests of the client and not to betray trust. This does not totally trump wider social ethical obligations, though it can conflict with them quite strongly, for example, a lawyer defending a murderer in court even if $\mathrm{s} /$ he is personally certain they are guilty. Within ICT professional ethics, there may be cases when the social good would be seen as more important than the request of the client, e.g. a company requesting illegal surveillance, or an HR algorithm which disadvantaged women or black people. In these cases often, though not always, it is a rushed, short-cut approach which can inadvertently cause the creation of biased systems or noncompliant use of technologies. Thus the desire of company to reduce costs and increase profits can be in conflict with professional ethics.

Recent discussions on improving professional codes of ethics suggest moving away from a rule-based approach to a more principles-based approach. The American Institute of Certified Public Accountants (AICPA), for example, has recently added a new conceptual framework to their professional ethics by suggesting that all its members regard every questionable situation, circumstance, transaction, or relationship by attempting to view it through the eyes of an imagined reasonable third party (Spalding and Lawrie, 2019). There is also some suggestion to more closely link the approach to professional ethics with the existing practices and ethos of the relevant profession. This is demonstrated in recent work on the use of pragmatic care and design principles to inform engineering ethics (Nair and Bulleit, 2020) and incorporating ethics into the software design process (Gordon et al., 2020). Furthermore, recent work has also examined means of 'ethical deliberation' as a remedy to the uncertainties of the software design process, whilst acknowledging availability and constraints of time and resources allocated to projects (Gogoll et al., 2021).

\subsection{Professional Ethics Documentation}

Ethics in most professions is not only implicit, but also explicitly codified in some way as a reference document. Similar to a BoK, this documentation is both aspirational and representational of the ethics that the profession espouses and enacts. In our study of ICT BoKs, we identified multiple methods of documenting ICT professional ethics, including codes, case studies, educational materials, and references to legal cases (ACM). Codes of Ethics usually include some general ethical principles then become more specific about how that might translate into actual conduct in practice. Some codes explicitly acknowledge that professionals may face situations where they perceive an ethical dilemma or a case where two ethical principles may be in conflict (e.g. privacy and public safety) and deciding on the 'right thing to do' is not a simple case of applying a certain ethical principle. Both the Association for Computing Machinery (ACM) and the Australian Computer Society (ACS) include case studies in their ethics material to allow education and discussion around ways to approach these dilemmas. The ACS in particular offer detailed guidance on how the case studies relate to particular parts of the codes of ethics.

The ACM discussion of the legal use of the ACM code is interesting. It has been used as a legal defence for professionals to refuse government requests for customer information, arguing that the right to privacy is a stronger ethical force that legal compliance if (and only if) that legal compliance is clearly anti-privacy. This demonstrates that professional codes of ethics, whilst not legally binding, are recognised within the legal profession as indicative of a profession's accepted practice and have a high standing. It is hard to envisage that if the ACM had failed to codify their ethics that a similar argument could be made just because 'the ACM generally thinks that privacy is very important'.

\section{Method}

\subsection{Selection for review}

The criteria for the inclusion of ICT BoKs in the review were authority, i.e. the BoK is from an established and known institution, and availability, i.e. it is possible to locate and access the BoK. A review of significant ICT BoKs involved initial selection through a literature search using the search terms 'BoK', 'Body of knowledge', or 'Bodies of Knowledge', combined with different ICT related terms, ranging from broader (ICT, IT, computer, software, etc.) to narrower terms (project, data, service, security, etc.) to ensure comprehensive coverage. This was extended through searching websites from authoritative bodies and sources in the field. These BoKs indicate what is considered relevant knowledge for their specified field. The selection of BoKs were verified through two 
stakeholder meetings with experts in the ICT professionalism field who were selected on the basis they had published on the topic or contributed as experts to previous EC ICT Professionalism projects. Thus, the list cannot claim to be exhaustive, but it is reasonably representative.

Twenty-three BoKs were analysed in total. Six BoKs addressed the generic level of ICT management and seventeen focused on more detailed specialist areas. ICT has many different specialisms thus there are more specialist BoKs than generic BoKs but the more general BoKs often have a broader influence. As BoKs are often part of a suite of resources for a profession (i.e. knowledge infrastructure) including other items such as competence frameworks, codes of ethics and certification programmes, we also noted if the BoK referred to ethics material in related resources.

After examining how the BoKs incorporated ethics, we selected three, based on how well and thoroughly ethics was integrated in both their structure and content, and how that was further integrated with other tools of professional maturity, namely codes of ethics, curriculum guidelines and accreditation. In these high scoring cases, we reviewed how ethics was considered in the relevant BoK in more detail, examining key themes and drawing connections between different theoretical ethical approaches.

\subsection{Analysis methods}

We used content analysis through a reading of the full text of the BoKs and a final check using the search function in Word for ethics and related terms. Our first step was to ascertain where ethics was overtly incorporated within the overall content structure, i.e. scope, introduction, $\mathrm{KI} / \mathrm{KU}$ etc. We then further examined the ways in which ethics were explicitly present in the BoKs, i.e. in definitions and concepts, and links to the domain knowledge infrastructure. We reviewed whether ethics was included as core to the BoK, i.e. as a knowledge item or knowledge unit within the knowledge structure. Next we examined where ethics was mentioned in other parts of the BoK, for example the introduction or purpose section. If the BoK had a separate references or literature section, we reviewed this list for sources related to ethics. The final analysis looked at how the BoK linked ethics to the domain knowledge infrastructure, i.e. to other professional resources such as codes of ethics, curriculum guidance, or incorporation into a professional certification process.

\section{Results}

\subsection{Summary Results from all BoKs}

The results are analysed in two stages. First, we provide an overview of key findings with a summary table describing the main findings. Second, we explore how ethics is portrayed in three of the BoKs, selected due to their higher stage of professional maturity, in more detail.

Table 1 shows the results from the initial analysis and provides an overview of the BoKs surveyed, whether and how they included ethics, and if there were other ethics content sources available such as a code of ethics and/or guide to professional conduct. The main finding is that all but one of the BoKs we surveyed did include ethics in some way, the only exception being the 'Enterprise Architecture Body of Knowledge'. Even in this case the BoK mentioned ethics as important, which would be developed in the future. We then carried out some detailed analysis of the BoKs that included ethics, to ascertain if they could be usefully further categorised. We examined them to see where and how exactly ethics was discussed in the BoK. The results show the following key findings:

\subsubsection{Findings related to ethics within structure of BoK}

- Ethics is most commonly a knowledge unit (18/23)

- Ethics in over half of BoKs is included as part of introduction/purpose/overview (12/23)

- Ethics is rarely the heading of a general knowledge area $(4 / 23)$

\subsubsection{Findings related to ethics within definitions and concepts of the BoK}

- Ethics is rarely explicitly linked to leadership (2/23)

- Ethics is sometimes included in definition of professionalism (5/23)

\subsubsection{Findings related to link of ethics in BoK to other professional resources or processes}

- $\quad$ Ethics included in the definition of professionalism tends to make it part of the certification process $(3 / 5)$

- The 2 that include professionalism but do not certify ethics have no certification process at all 
Table 1: Overview of BoKs and ethics (*“n/a": item not applicable i.e. non-existent. **"?”: no data could be found)

\begin{tabular}{|c|c|c|c|c|c|c|c|c|c|}
\hline BoK Title & 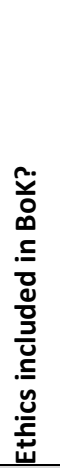 & 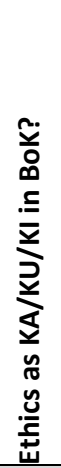 & 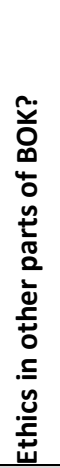 & $\begin{array}{l}\text { How is ethics included in other } \\
\text { parts? }\end{array}$ & 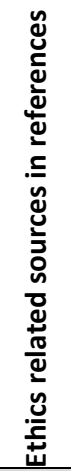 & 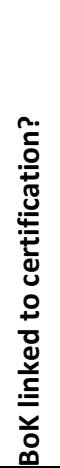 & 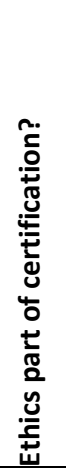 & 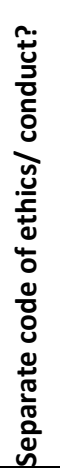 & 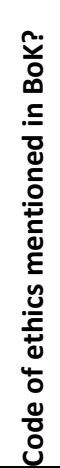 \\
\hline \multicolumn{10}{|l|}{ GENERAL BOKs } \\
\hline $\begin{array}{l}\text { Core Body of Knowledge for } \\
\text { ICT Professionals - ACS, } 2015\end{array}$ & $\checkmark$ & $\checkmark$ & $\checkmark$ & In definition ICT profession & $\mathrm{n} / \mathrm{a}$ & $\checkmark$ & $\checkmark$ & $\checkmark$ & $\checkmark$ \\
\hline $\begin{array}{l}\text { Common BoK for Computing } \\
\text { and ICT - CIPS, } 2012\end{array}$ & $\checkmark$ & $\checkmark$ & $\checkmark$ & $\begin{array}{l}\text { In vision of BoK, in definition ICT } \\
\text { professional }\end{array}$ & $\checkmark$ & $\checkmark$ & $\checkmark$ & $\checkmark$ & $\checkmark$ \\
\hline $\begin{array}{l}\text { Digital Practitioner BOKs - } \\
\text { TOG, } 2019\end{array}$ & $\checkmark$ & $\checkmark$ & $x$ & $\mathrm{n} / \mathrm{a}$ & $\mathrm{n} / \mathrm{a}$ & $x$ & $x$ & $x$ & $\mathrm{n} / \mathrm{a}$ \\
\hline $\begin{array}{l}\text { The European Foundational } \\
\text { ICT BoK - EC, } 2015\end{array}$ & $\checkmark$ & $\checkmark$ & $\checkmark$ & In definition ICT professional & $\mathrm{n} / \mathrm{a}$ & $x$ & $x$ & $x$ & $\mathrm{n} / \mathrm{a}$ \\
\hline $\begin{array}{l}\text { Domain description bachelor } \\
\text { of ICT - HBO-I, } 2019\end{array}$ & $\checkmark$ & $\checkmark$ & $x$ & $\mathrm{n} / \mathrm{a}$ & $\mathrm{n} / \mathrm{a}$ & $x$ & $x$ & $x$ & $\mathrm{n} / \mathrm{a}$ \\
\hline $\begin{array}{l}\text { Computer Science BoK - } \\
\text { ACM/IEEE, } 2013\end{array}$ & $\checkmark$ & $\checkmark$ & $\checkmark$ & $\begin{array}{l}\text { Work ethic critical; part of } \\
\text { curriculum. Professional } \\
\text { responsibilities }\end{array}$ & $\checkmark$ & $\checkmark$ & $\checkmark$ & $\checkmark$ & $\checkmark$ \\
\hline \multicolumn{10}{|l|}{ SPECIALISED BOKs } \\
\hline $\begin{array}{l}\text { Business Analysis BoK v3 - } \\
\text { IIBA, } 2015\end{array}$ & $\checkmark$ & $x$ & $\checkmark$ & $\begin{array}{l}\text { As behavioural characteristic in } \\
\text { competences: short description }\end{array}$ & $\mathrm{n} / \mathrm{a}$ & $\checkmark$ & $x$ & $\checkmark$ & $x$ \\
\hline $\begin{array}{l}\text { Business Process Management } \\
\text { Common BoK 3.0 - ABPMP, } \\
2013\end{array}$ & $\checkmark$ & $x$ & $\checkmark$ & $\begin{array}{l}\text { Code of ethics: practical } \\
\text { description of responsibilities }\end{array}$ & $\mathrm{n} / \mathrm{a}$ & $\checkmark$ & ?* $^{*}$ & $\checkmark$ & $\checkmark$ \\
\hline $\begin{array}{l}\text { Cyber Security BoK } 2.0 \text { - NCSC, } \\
2017\end{array}$ & $\checkmark$ & $\checkmark$ & $\checkmark$ & $\begin{array}{l}\text { ethical responsibilities', ethical } \\
\text { hackers }\end{array}$ & $\checkmark$ & $x$ & $x$ & $x$ & $\mathrm{n} / \mathrm{a}$ \\
\hline $\begin{array}{l}\text { EDSF Data Science BoK v2 - } \\
\text { IABAC, } 2019\end{array}$ & $\checkmark$ & $\checkmark$ & $x$ & $\mathrm{n} / \mathrm{a}$ & $x$ & $\checkmark$ & $\checkmark$ & $x$ & $\mathrm{n} / \mathrm{a}$ \\
\hline $\begin{array}{l}\text { Enterprise Architecture BoK - } \\
\text { EABOK Consortium, } 2014\end{array}$ & $x$ & $x$ & $x$ & $\begin{array}{l}\text { (Code of ethics important in } \\
\text { future) }\end{array}$ & $x$ & $x$ & $x$ & $x$ & $\mathrm{n} / \mathrm{a}$ \\
\hline $\begin{array}{l}\text { Enterprise Information } \\
\text { Technology BoK - IEEE/ACM IT, } \\
2017\end{array}$ & $\checkmark$ & $\checkmark$ & $x$ & $\mathrm{n} / \mathrm{a}$ & $x$ & $x$ & $x$ & $x$ & $\mathrm{n} / \mathrm{a}$ \\
\hline $\begin{array}{l}\text { IT Architecture BoK } 2.0 \text { - IASA, } \\
2019\end{array}$ & $\checkmark$ & $\checkmark$ & $x$ & $\mathrm{n} / \mathrm{a}$ & $x$ & $\checkmark$ & $?$ & $\checkmark$ & $\checkmark$ \\
\hline $\begin{array}{l}\text { IT Security Essential BoK - U.S. } \\
\text { Dept.Homeland Security, } 2007\end{array}$ & $\checkmark$ & $\checkmark$ & $x$ & $\mathrm{n} / \mathrm{a}$ & $\mathrm{n} / \mathrm{a}$ & $x$ & $x$ & $x$ & $\mathrm{n} / \mathrm{a}$ \\
\hline $\begin{array}{l}\text { Open Service Management } \\
\text { Foundation BoK - OSM } \\
\text { Alliance, } 2017\end{array}$ & $\checkmark$ & $\checkmark$ & $x$ & $\mathrm{n} / \mathrm{a}$ & $\mathrm{n} / \mathrm{a}$ & $x$ & $x$ & $x$ & $\mathrm{n} / \mathrm{a}$ \\
\hline $\begin{array}{l}\text { Project Management } \\
\text { Professional BoK } 6 \text { - PMI, } 2017\end{array}$ & $\checkmark$ & $\checkmark$ & $\checkmark$ & $\begin{array}{l}\text { Term used in factors. Being ethical } \\
\text { as quality of a leader. }\end{array}$ & $\checkmark$ & $\checkmark$ & $\checkmark$ & $\checkmark$ & $\checkmark$ \\
\hline Quality BoK - ASQ, 2009 & $\checkmark$ & $\checkmark$ & $x$ & $\mathrm{n} / \mathrm{a}$ & $\mathrm{n} / \mathrm{a}$ & $\checkmark$ & $?$ & $\checkmark$ & $x$ \\
\hline $\begin{array}{l}\text { Scrum BoK } 3.0 \text { - SCRUM study, } \\
2016\end{array}$ & $\checkmark$ & $\checkmark$ & $x$ & $\mathrm{n} / \mathrm{a}$ & $\mathrm{n} / \mathrm{a}$ & $\checkmark$ & $?$ & $x$ & $\mathrm{n} / \mathrm{a}$ \\
\hline $\begin{array}{l}\text { Software Engineering BoK - } \\
\text { IEEE, } 2014\end{array}$ & $\checkmark$ & $\checkmark$ & $x$ & $\mathrm{n} / \mathrm{a}$ & $\checkmark$ & $\checkmark$ & $?$ & $\checkmark$ & $\checkmark$ \\
\hline $\begin{array}{l}\text { Systems Engineering BoK - } \\
\text { IEEE, } 2018\end{array}$ & $\checkmark$ & $\checkmark$ & $\checkmark$ & $\begin{array}{l}\text { Term mentioned in knowledge } \\
\text { areas }\end{array}$ & $\checkmark$ & $x$ & $x$ & $\checkmark$ & $\checkmark$ \\
\hline
\end{tabular}




\begin{tabular}{|c|c|c|c|c|c|c|c|c|c|}
\hline BoK Title & 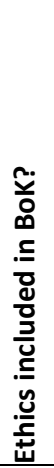 & 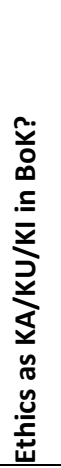 & 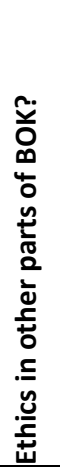 & $\begin{array}{l}\text { How is ethics included in other } \\
\text { parts? }\end{array}$ & 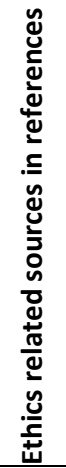 & 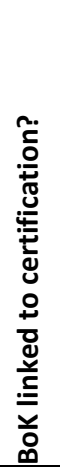 & 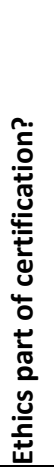 & 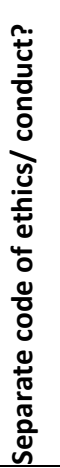 & 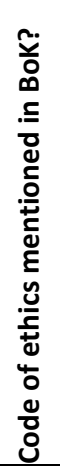 \\
\hline $\begin{array}{l}\text { The Information Management } \\
\text { BoK - Blytheway, } 2014\end{array}$ & $\checkmark$ & $x$ & $\checkmark$ & $\begin{array}{l}\text { Ethical principles as part of case } \\
\text { example }\end{array}$ & $\mathrm{n} / \mathrm{a}$ & $x$ & $x$ & $x$ & $\mathrm{n} / \mathrm{a}$ \\
\hline Usability BoK - UXPA, 2012 & $\checkmark$ & $x$ & $\checkmark$ & $\begin{array}{l}\text { Terms 'ethical considerations' and } \\
\text { 'ethical issues' used }\end{array}$ & $\mathrm{n} / \mathrm{a}$ & $\checkmark$ & $?$ & $\checkmark$ & $x$ \\
\hline $\begin{array}{l}\text { Wireless Engineering BoK } 2 \text { - } \\
\text { IEEE, } 2012\end{array}$ & $\checkmark$ & $\checkmark$ & $x$ & $\mathrm{n} / \mathrm{a}$ & $x$ & $x$ & $x$ & $\checkmark$ & $\checkmark$ \\
\hline Total (out of 23 BoKs) & 22 & 18 & 11 & & 5 & 11 & 4 & 11 & 8 \\
\hline
\end{tabular}

We found two main approaches to including ethics in ICT BoKs, which are combined in some cases. The first approach includes ethics within the structure of the BoK as a general Knowledge Area (KA). Including ethics as a Knowledge Area brings it up a level of abstraction, strengthening its position and increasing visibility and coverage, though this approach is rare. More commonly, ethics is covered as a specific Knowledge Unit (KU) or Item (KI). This approach positions ethics as an essential piece of knowledge within the BoK, but it remains subordinate to the knowledge structure rather than being an overall or generally applicable concept. In most cases, where ethics was addressed within a KI or KU, the term is just mentioned without any further explanation or discussion. As a second option, ethics may be included as part of the introduction, mission, or purpose of the BoK. Here, ethics is presented as a general context but may not be intrinsically incorporated into the core of the BoK. Rarely, is ethics both discussed in the mission and identified as a core and common required knowledge area.

\subsection{Analysis of selected BoKs}

Three BoKs were selected for more detailed analysis. They were chosen because they had a high level of BoK maturity and linked closely to related ethical and professional documentation in their field such as certification and codes of ethics. All three were general ICT BoKs, rather than specialism-focused, so were more likely to offer broader insights for other professions. The three BoKs that were selected are as follows:

Core Body of Knowledge for ICT Professionals - Australian Computer Society (ACS), 2015

Common BoK for Computing and ICT - Canada's Association of Information Technology Professionals (CIPS), 2012

Computer Science BoK - Association for Computing Machinery (ACM)/Institute of Electrical and Electronics Engineers (IEEE), 2013

We were interested to see if the approach in these BoKs to describing or codifying knowledge about ethics could provide useful insights for BoKs and related professions that wish to improve ethical standards and develop professional maturity. In particular, we were seeking any evidence of the use of ethical theories in how ethics and knowledge about ethics were discussed in these BoKs. We present our findings under key themes or characteristics that emerged from these selected BoKs and review to find whether we can establish a connection between the BoKs and one or more theoretical ethical approaches.

Table 2: Overview of BoK ethical themes and theoretical approaches to ethics

\begin{tabular}{|l|l|l|l|}
\hline & Virtue & Deontological & Consequential \\
\hline ICT professionalism \& societal aspiration & $\checkmark$ & & \\
\hline Ethical theories in teaching & $\checkmark$ & & \\
\hline Diversity and inclusion & $\checkmark$ & $\checkmark$ & $\checkmark$ \\
\hline Limits of knowledge & & $\checkmark$ & $\checkmark$ \\
\hline Responsibility \& consequence & & & $\checkmark$ \\
\hline
\end{tabular}




\begin{tabular}{|l|l|l|l|}
\hline & Virtue & Deontological & Consequential \\
\hline Power \& inferred trust & $\checkmark$ & & \\
\hline Compliance & & $\checkmark$ & \\
\hline
\end{tabular}

\subsubsection{ICT professionalism and societal aspiration}

The selected BoKs make strong aspirational claims about ICT and computing as a profession, its potential to dramatically affect society for good or ill, and the resultant responsibility of the ICT professional. This is stronger in the ACM/IEEE BoKs but the CIPS BOK makes explicit reference to the CIPS vision document ' $\mathrm{CIPS}$ in the $21^{\text {st }}$ century'. This suggests an appeal to virtue ethics as it encourages intrinsic ethical values and a sense or personal ethical responsibility. It is also informative as it explains the enormous social and ethical implications of ICT and corrects immediately any view that ICT is merely a technical subject and profession. It is reasonable to conclude that in the more mature BoKs, the nature of the profession is explicitly extended beyond the technical and a conscious effort is made to instil a sense of responsibility and pride.

\subsubsection{Ethical theories in teaching}

The ACM/IEEE and the ACS discuss the nature of ethical theories and include them in guidance on what should be taught to students. The stated goals are to equip students with a deep understanding of ethics and to learn to apply theories and models in different situations. A key insight is that theories of ethics should be included but they must be integrated and related to specific problems or technologies and grounded in a discussion on what shared values will inform them. The ACS BoK states that this kind of ethical knowledge will take time for a professional to develop as they gain experience. Thus it is both abstract and grounded in practice. The CIPS BoK includes ethical theories in its 'Professionalism and Ethics in Computing and IT' Knowledge Area and states that professionals should be able to deal with and manage ethical dilemmas. This Knowledge Area is also labelled Knowledge Area $A$ and is the first one described in the BoK, which may possibly indicate primacy though this is not stated. The CIPs BOK categorises its knowledge into three levels and ethics is required at the highest level of understanding (application). The CIPS BoK also has an extensive ethics section in their reference list. Not all of the ethics references link directly to ICT, suggesting that a broader theoretical understanding of ethics is encouraged. None of the selected BoKs explicitly favours one or other ethical approach, nor select one as most appropriate to ICT.

\subsubsection{Diversity and inclusion}

This is covered both in the sense that it is an ethical obligation to be aware of and respect diversity in race, gender, disability, etc. and also in acknowledging important cultural or national differences to professional ethics. Local adaptation of general values is generally seen as preferable to a full-scale acceptance of moral cultural relativism. Diversity of cultures and potential conflict is also covered, with guidance provided on approaching this through related professional documentation. Ethics is not just seen as an individual decision on particular work place issues but in most cases is linked to wider social and environmental concerns such as diversity, inclusion, and sustainability. The ethical approach taken in these sections of the BoKs is generally more pragmatic or consequentialist, with some appeal to virtue ethics. In many cases, of course, the equality and diversity issues are legally enforced so they are rule led or deontological but this has not been set by the ICT profession. Within ICT BoKs these values are portrayed as a given that one must respect and follow.

\subsubsection{Limits of knowledge}

A theme perhaps of most pertinence and interest to $\mathrm{KM}$ is that the very action of being clear on the content and boundaries of one's professional knowledge is identified in itself as a sign of ethical maturity. If ICT professionals are clear on their knowledge area and professional responsibility, they have an obligation not to act outside of this area and to honestly report if they are asked to operate outside of them. Professionalism is all about the limits of knowledge and the public acknowledgement of expertise held by the professional. The honest and explicit line between knowledge and ignorance is key. Failure to stay within one's areas of expertise can both be illegal and have terrible consequences, though this is not explicitly spelled out in its coverage within the BoKs. Concern for the limits of knowledge has strong philosophical foundations. The Socratic tradition emphasises very strongly the importance of humility and honest acknowledgement of ignorance (Plato, 399AD).

\subsubsection{Responsibility and consequences}

ICT is acknowledged in all the selected BoKs as having a major impact on society and that many safety critical systems and infrastructures depend upon it. In the CIPs BoK, there is a specific Knowledge Item on Safety Critical Systems, which includes Public Safety as a component. Risk and safety are addressed in all three selected BoKs. 
The discussion around these encompasses all theoretical approaches to ethics. An ICT professional has an ethical responsibility (virtue ethics), the consequences of error are potentially catastrophic (consequentialism), and there are also legal implications and rules (deontological ethics) surrounding these high-risk areas.

\subsubsection{Power and inferred trust}

There is strong theme in the BoKs that power gained by expert knowledge must not be abused. This is perhaps particularly urgent in ICT as it is often invisible power that the public are not aware of. The technology is also beyond what most in the general population can understand. This is usually addressed in the introduction section to operate as reminder of why it is important to be clear on knowledge.

\subsubsection{Compliance}

Knowledge of the relevant codes of ethics, legal obligations, and organisational procedures that help enforce ethics, such as whistle blowing, are also part of the knowledge content of these BoKs. This is in one sense a deontological approach and also makes clear that professional ethics is not the activity of a 'lone hero' but should be enabled by good management practices and effective legal sanctions within wider society. Thus is it included a specific knowledge item and, naturally, its inclusion depends upon reasonable professional maturity in terms of the existence of a code of ethics.

\section{Discussion}

This research provides some analysis and discussion on the relationship between knowledge, ethics and professionalism through the study of ethics within ICT Bodies of Knowledge. It has shown how BoKs are both implicit and explicit in their approach to KM and that they have the capacity to integrate ethical aspiration, professional mission, and detailed technical knowledge. A particular area of current concern regarding ICT ethics is transparency in the growing field of Artificial Intelligence. This study provides a perspective that can help ground some of the current 'moral panic' regarding such ethical issues in the ICT domain. It demonstrates that one approach to tame this fear is to carefully articulate knowledge and directly relate it to professional identity and practice. The careful connection between the clarification of knowledge limits and ethics in these BoKs offers some insights into why there is so much public concern around Al, as with Al those limits are very difficult to define transparently.

It is clear from the analysis of the more mature BoKs that theoretical approaches to ethics are not explicitly called out as a justification for specific types of ethical knowledge but that all the major ethical theories are implicitly incorporated. The more mature BoKs require that ethical theories are part of the core knowledge of ICT professionals and this is generally explicitly linked to specific actual issues that will arise in practice. The stated aim is to equip ICT professionals with the theoretical tools and understanding so they can successfully identify assess and manage ethical issues in the workplace. This can be understood as a method to facilitate the integration of theoretical knowledge with personal values and professional practice.

This issue of integration and connection between theoretical knowledge and practice is echoed or reflected in the role that ethics appears to take in the maturity of the ICT profession. The highly developed BoKs we surveyed, which contained a well-considered and integrated discussion of ethics, also had the strongest connections to other various aspects of professional practice and knowledge such as accreditation. At the higher end of maturity, BoKS that include ethics in both their definition of professionalism and their certification and educational resources have more effective ways of sharing knowledge about ethics within their field. How a profession deals with knowledge and how it integrates this into its other structures is a sign of professional maturity.

\section{Conclusions and future work}

This section will examine two main conclusions of this work, firstly in terms of KM and secondly in terms of its implications for other professions apart from ICT. The first conclusion is what this work can mean for the development of KM as a discipline. As discussed in our literature review, we did not find any KM literature on the development or use of BoKs. BoKs are a fascinating combination of explicit knowledge that refers to implicit knowledge. They also have a complex purpose of sharing knowledge and linking to other knowledge processes such as education. Our work has shown how knowledge within BoKs contains ethical knowledge at both an abstract and more concrete level. BoKs are essentially a starting point for 'putting knowledge to action' and warrant further study as both a method and approach. Higher quality BoKs and a more widespread 
understanding of their role may help mitigate growing concerns about professional values and ethics in businesses and wider society.

Secondly, the insights that have been provided on the relationship between professional ethics and BoKs can also help inform other professions and new emerging ICT specialities. It demonstrates that ethics and expert knowledge cannot be seen as separate areas. The most benefit is gained when a profession carefully articulates the nature of ethics as knowledge and ensures coordination between different types of professional documentation and practices. It also shows that it is not surprising if the development of BoKs and professional ethics can cause conflict and disagreement. This will not be straightforward as professional knowledge is often disputed, and issues of power and identity will surface. As BoKs are often the first stage of professional maturity for new professions, it also shows that the considered inclusion of ethics into a BoK makes a solid ground for ethics in other professional processes such as education. Finally, the underlying assumption around most research and policy work on ICT professionalism is that it is playing 'catch up' with the more established professions such as Medicine and Law, which are highly regulated and have serious sanctions for professional misconduct. It might, however, be useful to critically engage with how these professions actually articulate knowledge about ethics in their BoKs and associated processes and see if the newer emerging profession of ICT may be able to inform or provide new insights into more established professions.

In terms of future work on the specific topic of ethics and professional knowledge within ICT, a more detailed analysis of how other professional documentation and resources consider ethics would be a useful next step. How exactly is ethics covered in ICT codes of ethics and other resources and processes such as accreditation guidance and curriculum development? In terms of the wider societal impact of ICT, a study of how ICT ethics is discussed in policy documents or relevant legal decisions would also increase our understanding of how knowledge about what is 'good' can actually be implemented in practice.

\section{Acknowledgments}

The authors would like to acknowledge the support of the European Commission in funding many ICT professionalism projects and in particular the key leadership role of André Richier.

\section{References}

Anon 2019. e-Competence Framework (e-CF): A common European Framework for the ICT Profession. EU: CEN.

Anon 2021. European Values for Ethics in Digital Technology - Research Report -. Ethics4EU. [online] EU Commission. Available at: <http://ethics4eu.eu/outcomes/european-values-for-ethics-in-technology-research-report/> [Accessed 2 Jul. 2021].

Anon 2021. IEEE SA - The IEEE Global Initiative on Ethics of Autonomous and Intelligent Systems. [online] Available at: $<$ https://standards.ieee.org/industry-connections/ec/autonomoussystems.html?_ga=2.169904416.14834609.1582105888-252767171.1582105888> [Accessed 7 Jul. 2021].

Aristotle, 350AD. The Nicomachean ethics.

CEDEFOP, 2016. ICT professionals: skills opportunities and challenges. [online] CEDEFOP. Available at: $<$ https://skillspanorama.cedefop.europa.eu/en/analytical_highlights/ict-professionals-skills-opportunities-andchallenges-2016> [Accessed 22 Apr. 2021].

Claxton, G., Lucas, B. and Webster, R., 2010. Bodies of Knowledge: how the learning sciences could transform practical and vocational education. London, UK: Edge/Centre for Real-World Learning.

Davies, M., 2004. Five Kinds of Ethics Across the Curriculum. Teaching Ethics., Spring(8), pp.1-4.

Davis, K., 2007. The Making of Our Bodies, Ourselves: How Feminism Travels across Borders. Next Wave: New Directions in Women's Studies. North Carolina, USA: Duke University Press.

Durkheim, É., 1912. The Elementary Forms Of Religious Life. Oxford University Press, USA.

Eraut, M., 1994. Developing Professional Knowledge and Competence. London: Falmer Press.

EU Commission, 2018. Ethics and Data Protection. Available at: <http://ec.europa.eu/research/participants/data/ref/h2020/grants_manual/hi/ethics/h2020_hi_ethics-dataprotection_en.pdf> [Accessed 13 Feb. 2019].

Floridi, L. and Taddeo, M., 2016. What is data ethics? Philosophical Transactions of the Royal Society A: Mathematical, Physical and Engineering Sciences, 374(2083), p.20160360. https://doi.org/10.1098/rsta.2016.0360.

Gavrilova, T. and Andreeva, T., 2012. Knowledge elicitation techniques in a knowledge management context. Journal of Knowledge Management, 16(4), pp.523-537. https://doi.org/10.1108/13673271211246112.

Gelles, D., 2019. Boeing 737 Max: What's Happened After the 2 Deadly Crashes. The New York Times. [online] 22 Mar. Available at: <https://www.nytimes.com/interactive/2019/business/boeing-737-crashes.html> [Accessed 7 Jul. 2021]. 
Gogoll, J., Zuber, N., Kacianka, S., Greger, T., Pretschner, A. and Nida-Rümelin, J., 2021. Ethics in the Software Development Process: from Codes of Conduct to Ethical Deliberation. Philosophy \& Technology. [online] https://doi.org/10.1007/s13347-021-00451-w.

Gordon, D., Collins, M., Becevel, A. and O, W., 2020. Incorporating Ethics Throughout the Software Development Process. In: INTED2020 Proceedings. [online] 14th International Technology, Education and Development Conference. Valencia, Spain: IATED.pp.8109-8116. Available at: <https://library.iated.org/view/GORDON2020INC> [Accessed 1 Apr. 2021].

Greenfield, A., 2017. Practices of the Minimum Viable Utopia. Architectural Design, 87(1), pp.16-25. https://doi.org/10.1002/ad.2127.

Hawley, N., Diskin, W., Pincus, J., Schwarz, A., Rome, E., Sable, B., Doress, P., de Long, J., Goldner, G., London, N., Perkins, B., Bell, R., Sanford, W., Berger, P., Martz, W., Candib, L., Ditzion, J., Driscoll, C. and Mann, N., 1971. Our Bodies Ourselves. [online] Boston, MA: The Boston Women's Health Collective. Available at: $<$ https://www.ourbodiesourselves.org/publications/the-nine-u-s-editions/> [Accessed 6 Jul. 2021].

Holmes, W., 1974. The Social Implications of the Australian Computer Society. The Australian Computer Journal, 6(3), pp.124-128.

Hursthouse, R. and Pettigrove, G., 2018. Virtue Ethics. In: E.N. Zalta, ed. The Stanford Encyclopedia of Philosophy, Winter 2018. [online] Metaphysics Research Lab, Stanford University. Available at: $<$ https://plato.stanford.edu/archives/win2018/entries/ethics-virtue/> [Accessed 31 Jan. 2020].

Kim, D., 2020. The SBOK? Looks like anyone can create a PM standard these days! Available at: <https://www.projectmanagement.com/blog-post/7084/The-SBOK---Looks-like-anyone-can-create-a-PM-standardthese-days->. [ Accessed 1 September 2021]

Koene, A., Clifton, C. and Hatada, Y., 2019. A governance framework for algorithmic accountability and transparency. Scientific Foresight Unit (STOA). [online] Publications Office European Parliament. Directorate General for Parliamentary Research Services. Available at: <https://data.europa.eu/doi/10.2861/59990> [Accessed 22 Apr. 2021].

Lemonne, E., 2018. Ethics Guidelines for Trustworthy AI. [Text] FUTURIUM - European Commission. Available at: $<$ https://ec.europa.eu/futurium/en/ai-alliance-consultation> [Accessed 7 Jul. 2021].

van der Linden, N., Siebes, C., Bonazzoli, F., Dimauro, M., Catteneo, G. and Kolding, M., 2017. Development and Implementation of a European Framework for IT Professionalism. European Commission.

Lynch, H., Bartley, R., Metcalf, J., Petroni, M., Ahuja, A. and David, S.L., 2016. Building digital trust: The role of data ethics in the digital age. [online] Available at: <https://www.accenture.com/ro-en/insight-data-ethics> [Accessed 19 Mar. 2021].

McLaughlin, S., Sherry, M., Carcary, M., O’Brien, C., Fanning, F., Theodorakis, D., Dolan, D. and Farren, N., 2012. e-Skills and ICT Professionalism Fostering the ICT Profession in Europe. The European Commission.

Mill, J.S., 1863. Utilitarianism. Parker, Son and Bourn.

Morris, P.W.G., 2001. Updating the Project Management Bodies of Knowledge. Project Management Journal, 32(3), pp.2130. https://doi.org/10.1177/875697280103200304.

Morris, P.W.G., Crawford, L., Hodgson, D., Shepherd, M.M. and Thomas, J., 2006. Exploring the role of formal bodies of knowledge in defining a profession - The case of project management. International Journal of Project Management, 24(8), pp.710-721. https://doi.org/10.1016/j.ijproman.2006.09.012.

Nair, I. and Bulleit, W.M., 2020. Pragmatism and Care in Engineering Ethics. Science and Engineering Ethics, 26(1), pp.6587. https://doi.org/10.1007/s11948-018-0080-y.

Nonaka, I., 1994. A Dynamic Theory of Organizational Knowledge Creation. Organization Science, 5(1), pp.14-37. https://doi.org/10.1287/orsc.5.1.14.

Penzenstadler, B., Fernández, D.M., Richardson, D., Callele, D. and Wnuk, K., 2013. The requirements engineering body of knowledge (rebok). In: 2013 21st IEEE International Requirements Engineering Conference (RE). IEEE.pp.377-379.

Peters, M., 2004. Education and the Philosophy of the Body: Bodies of Knowledge and Knowledges of the Body. In: L. Bresler, ed. Knowing Bodies, Moving Minds: Towards Embodied Teaching and Learning, Landscapes: the Arts, Aesthetics, and Education. [online] Dordrecht: Springer Netherlands.pp.13-27. https://doi.org/10.1007/978-1-40202023-0_2.

Plato, 399AD. The Apology of Socrates.

Rachels, J. and Rachels, S., 2019. The Elements of Moral Philosophy. New York: McGraw-Hill Education. .

Runciman, B., 2019. Real life ethical dilemmas. BCS Insights 2019 research. [online] British Computer Society.p.36. Available at: <https://cdn.bcs.org/bcs-org-media/2937/insights-ethical-dilemmas-2019.pdf>.

Rutz, M., 2013. Bodies of Knowledge in Ancient Mesopotamia: The Diviners of Late Bronze Age Emar and their Tablet Collection. Leiden: BRILL.

Saks, M., 2012. Defining a Profession: The Role of Knowledge and Expertise. Professions and Professionalism, 2(1), pp.1-10.

Sanz, L.F., Gómez-Pérez, J., Castillo-Martinez, A., Sanz, L.F., Gómez-Pérez, J. and Castillo-Martinez, A., 2018. Analysis of the European ICT Competence Frameworks. In: Multidisciplinary Perspectives on Human Capital and Information Technology Professionals. [online] IGI Global.pp.225-245. Available at: <https://www.igiglobal.com/gateway/chapter/198259> [Accessed 7 Feb. 2020].

Sefton, J.M., Shea, M. and Hines, C., 2011. Developing, Maintaining, and Using a Body of Knowledge for the Massage Therapy Profession. International Journal of Therapeutic Massage \& Bodywork, 4(3), pp.1-12. 
Sherry, X., 2013. National strategy for digital records: Comparing the approaches of Canada and China. International Journal of Information Management, 33(4), pp.697-701. https://doi.org/10.1016/j.ijinfomgt.2013.02.004.

Spalding, A.D. and Lawrie, G.R., 2019. A Critical Examination of the AICPA's New “Conceptual Framework" Ethics Protocol. Journal of Business Ethics, 155(4), pp.1135-1152. https://doi.org/10.1007/s10551-017-3528-0.

Spiegel, A., 2005. The Dictionary of Disorder. [online] The New York Times. Available at: <https://www.newyorker.com/magazine/2005/01/03/the-dictionary-of-disorders> [Accessed 7 Jul. 2021].

The European Commission, 2019. Europe investing in digital. [Text] Shaping Europe's digital future - European Commission. Available at: <https://ec.europa.eu/digital-single-market/en/europe-investing-digital> [Accessed 14 Apr. 2020].

Thornley, C., Ferguson, S., Weckert, J. and Gibb, F., 2011. Do RFIDs (radio frequency identifier devices) provide new ethical dilemmas for librarians and information professionals? International Journal of Information Management, 31(6), pp.546-555. https://doi.org/10.1016/j.ijinfomgt.2011.02.006.

Thornley, C.V., Murnane, S., McLoughlin, S., Carcary, M., Doherty, E. and Veling, L., 2018. The Role of Ethics in Developing Professionalism Within the Global ICT Community. International Journal of Human Capital and Information Technology Professionals (IJHCITP), 9(4), pp.56-71. https://doi.org/10.4018/IJHCITP.2018100104.

Tubella, A.A., Theodorou, A., Dignum, F. and Dignum, V., 2019. Governance by Glass-Box: Implementing Transparent Moral Bounds for Al Behaviour. In: Proceedings of the Twenty-Eighth International Joint Conference on Artificial Intelligence. [online] International Joint Conferences on Artifical Intelligence (IJCAI). Macao, China.pp.5787-5793. Available at: $<$ https://www.ijcai.org/proceedings/2019/802> [Accessed 22 Apr. 2021].

Yaghmaei, E., van de Poel, I., Christen, M., Gordijn, B., Kleine, N., Loi, M., Morgan, G. and Weber, K., 2017. Canvas White Paper 1 - Cybersecurity and Ethics. [SSRN Scholarly Paper] Rochester, NY: Social Science Research Network. https://doi.org/10.2139/ssrn.3091909. 